\title{
Oxford Specialist Handbooks in Anaesthesia - Paediatric Anaesthesia - Second Edition
}

\author{
Steve Roberts (Editor). Oxford Medical Publications, Oxford University Press, Oxford. \\ Published 2020. $£ 52.99,690$ pages. ISBN 978-0-19-875579-1
}

\author{
Simon Denning, BMedSci, MBBS, FRCA • David Faraoni, MD, PhD, FAHA
}

Received: 25 February 2020/Accepted: 26 February 2020/Published online: 9 March 2020

(C) Canadian Anesthesiologists' Society 2020

The second edition of the Oxford Specialist Handbooks in Anaesthesia - Paediatric Anaesthesia has a familiar feel as it conforms to the high standards of other reference texts in the Oxford series. The editor, Dr. Steve Roberts, has organized its 29 chapters written by numerous authors from the United Kingdom (UK) that have been organized into seven sections: Basic sciences, Perioperative care, Practical procedures, Pain management, Medical and surgical specialties, Syndromes and diseases, and Resuscitation, transfer, and medical emergencies. Each topic is presented concisely and clearly, with appropriate subheadings and links to further reading, as necessary. Most chapters are one to four pages in length.

At the beginning of the book is a useful list of symbols and abbreviations, and throughout the text there is good use of cross referencing to avoid unnecessary duplication. Although much of the information in this text is relevant to anesthesia practice worldwide, topics such as "Consent" focuses more on UK law and practice.

The first two chapters, in the Basic sciences section, offer a brief introduction to system-specific anatomy and physiology. The material is helpfully organized into airway and breathing, cardiovascular system, nervous system, and liver and kidneys divisions. Important pharmacological principles and commonly used agents in anesthesia practice are also discussed here. It is an ideal starting point for junior anesthesia trainees who are regularly encountering

S. Denning, BMedSci, MBBS, FRCA - D. Faraoni, MD, PhD, FAHA ( $\square)$

Department of Anesthesia and Pain Medicine, The Hospital for

Sick Children, Toronto, ON, Canada

e-mail: david.faraoni@sickkids.ca

Department of Anesthesiology and Pain Medicine, University of Toronto, Toronto, ON, Canada new agents and preparing for examinations. The anesthetic agents are described using a relatively uniform structure, making the information easily accessible for reference purposes. It covers each agent's use, mechanism of action, basic pharmacokinetics, and dosing recommendations.

Sections 2, 3, and 4 cover a considerable volume of practical information that will be valuable to trainees and consultants alike. Section 2, on perioperative care, includes practical tips for everything from preoperative assessment and preparation, induction and intraoperative care, to postoperative management. A wide-ranging overview of anesthetic equipment is included with relevant technical tables and black-and-white photographs where necessary. I found particularly interesting the portion of Chapter 7 that outlines potential intraoperative problems, including laryngospasm, massive hemorrhage, and anaphylaxis. Each issue is presented with a definition, causes, management, and prevention (if possible). It is an excellent resource for preparing oneself for addressing any of these issues but also for cognitive de-loading if one happen to have this text close by when needed.

Section 3, on practical procedures, is likely to be the chapter clinicians will most often revisit. Its Chapter 9 examines advanced airway management and introduces the reader to difficult airway etiologies and assessments. It goes on to detail planning and management with the numerous advanced airway manoeuvres and varied equipment that may be available in practitioners' institutions, including emergency front-of-neck access and tracheostomy. This subject is followed by advanced vascular access, with a focus on the use of ultrasound to cannulate vessels, and an overview of the equipment that can be used for central and arterial access. The section concludes with Chapter 11, a detailed look at 20 regional anesthetic techniques, including neuraxial, truncal, and 
upper- and lower-limb blocks. It should be considered a basic toolkit for anyone looking to provide regional anesthesia for their patients. These comprehensive descriptions of the techniques include the indications and contraindications, relevant anatomy, landmark- and ultrasound-guided techniques, dosing recommendations, and potential complications.

The regional anesthesia chapter segues nicely into Section 4, which addresses pain management and explores the challenge of pain assessment in children. It is relatively short and focused. The hugely important considerations of acute pain management include opioid analgesia followed by both pharmacological and physiological adjuncts.

Approximately one-third of the textbook, Section 5, is devoted to medical and surgical specialties. Chapters' subjects range from neonatal anesthesia and the concepts of day-case surgery to techniques for the management of earnose-throat, neurosurgical, and orthopedic procedures. There is a wealth of knowledge imparted here, with the chapters providing general overviews and general principles before detailing guidance and suggestions for the perioperative management of many common procedures within those specialties. Section 5, combined with Section 6, emphasizes why Oxford Specialist Handbooks in Anaesthesia - Paediatric Anaesthesia 2nd edition comes into its own as a reference text. Altogether, 24 comorbidities and syndromes (ranging from asthma to mucopolysaccharidoses) that one may encounter in pediatric practice are explored. Their etiology, clinical features (in a systems-based approach where suitable), and perioperative management are presented in a concise, digestible style. Whether one has been practicing for many years or is just starting out in anesthesia, there are valuable learning points throughout these sections.

The book concludes with an excellent overview of medical emergencies, management of the critically ill child, and resuscitation. It includes the use of many handy diagrammatic algorithms from Resuscitation $U K$ and The UK Sepsis Trust, useful checklists for pediatric transfer, and an extensive list of resuscitation drugs, indications, and doses.

In summary, this overview of pediatric anesthesia offers abundant information that can be accessed as needed because of the book's suitably succinct nature and excellent layout. It would be a good investment for any anesthesiologist with an interest in pediatric anesthesia, especially those in training or with upcoming examinations.

Conflicts of interest None.

Funding statement None.

Editorial responsibility This submission was handled by Dr. Hilary P. Grocott, Editor-in-Chief, Canadian Journal of Anesthesia.

Publisher's Note Springer Nature remains neutral with regard to jurisdictional claims in published maps and institutional affiliations. 